\title{
Osseus: A Method Based on Artificial Intelligence and Electromagnetic Waves for Ancillary Diagnosis of Osteoporosis
}

Gabriela Albuquerque1 ( $\nabla$ gabriela.albuquerque@lais.huol.ufrn.br)

Advanced Technological Innovation Nucleus - NAVI

Agnaldo Cruz ${ }^{1}$

Advanced Technological Innovation Nucleus - NAVI

Dionísio Carvalho'

Advanced Technological Innovation Nucleus - NAVI

Nadja Mayrink'

Advanced Technological Innovation Nucleus - NAVI

Bruno Pinheiro'

Advanced Technological Innovation Nucleus - NAVI

Antonio Campos ${ }^{1}$

Advanced Technological Innovation Nucleus - NAVI

Josivan Gomes Lima²

Hospital Universitário Onofre Lopes

Jorge Henriques

Centre for Informatics and Systems of the University of Coimbra

Ricardo Valentim ${ }^{1}$

Hospital Universitário Onofre Lopes

\section{Research Article}

Keywords: Osseus, medical device, osteoporosis, diagnosis, bone mineral density

Posted Date: November 30th, 2021

DOI: https://doi.org/10.21203/rs.3.rs-1101186/v1

License: (1) (i) This work is licensed under a Creative Commons Attribution 4.0 International License.

Read Full License 


\section{Abstract}

Background: Osteoporosis is characterized by low bone mineral density, which causes fractures and compromises people's quality of life. Diagnostic devices for assessing this health condition, such as Dual Energy X-ray Absorptiometry (DXA), are very costly. Therefore, it is impracticable to meet the demand for tests in Brazil's 5,568 municipalities. Given that, we proposed a pre-clinical validation of a prototype developed to aid bone mineral density classification. Thus, Osseus integrates a microcontroller with other peripheral devices to measure the electromagnetic permittivity at the middle phalanx of the middle finger, with two antennas operating in the $2.45 \mathrm{GHz}$ frequency range. Using Artificial Intelligence to identify risk factors alongside signal attenuation measurement indicates the need for DXA.

Results: We conducted tests with plaster, Galliformes, and porcine bones. Comparison of the measurements of the original and mechanically altered samples have demonstrated that the device can handle the complexity of the tissues within the bone structure and characterize its microarchitecture.

Conclusions: Osseus is a prototype and has been preliminarily validated. There is a lack of validation studies with the reference/gold standard that are currently under development. Osseus enables early detection of osteoporosis, reduces costs, and optimizes high-complexity testing referrals.

\section{Introduction}

Brazil is endowed with one of the largest and most complex public health systems worldwide. Thus, it provides for the Brazilian population comprehensive, universal, and free-of-charge access to healthcare. Primary health care (PHC) is the gateway to Brazil's Unified Health System (SUS, for its acronym in Portuguese). Since its implementation, SUS has been consolidating advances toward universal health coverage, therefore reaching $58.2 \%$ of the population [1]. A vast literature attributes improved outcomes, lower unnecessary hospitalization rates, and lower costs to health systems to a well-structured primary health care setting [2-4]. A 2020 study, conducted with a panel of Brazilian experts, presented as one of its recommendations for increasing the resoluteness and for the sustainability of the Brazilian health system, the need to promote prevention-oriented technology incorporation at the PHC level, using information technologies and diagnostic and therapeutic devices [5].

Osteoporosis is often referred to as a silent disease. The affected individuals are exposed to the risk of having fractures and consequent deterioration in their quality of life, impairing their mobility and autonomy. Every three seconds, someone has a fracture related to the disease [6]. By 2050, the incidence of hip fractures is projected to increase by $310 \%$ in men and $240 \%$ in women [7]. What is more, this proportion significantly increases with age. A study across four Latin American countries [8] estimated the number of fractures in 2018 and 2022 among adults aged 50 to 89 years and the annual cost of osteoporosis in such nations.

By 2022, for instance, the number of osteoporotic fractures in Brazil is predicted to increase by $14 \%$ compared to 2018 [8]. On top of that, the country's yearly cost of the disease is $\$ 309,507,247$, 
medications, tests, hospitalizations, surgeries, and productivity loss included. Therefore, it is essential to diagnose and treat the disease early to implement preventive measures for mitigating the occurrence of osteoporotic fractures. The disease diagnosis is made using the Dual Energy X-ray Absorptiometry (DXA) assessment method. It can be applied to the femur, lumbar spine, and forearm [9]. In Brazil, the number of DXA devices in use is 2,394 [10], with uneven distribution across the country (Figure 1). Yet, such devices are mostly available in large urban centers, and at higher-level health care facilities, so it is insufficient for the entire population to have access. Besides, the waiting time for getting a bone density test is up to six months in the public health system, SUS [11].

In addition to DXA, other techniques can also aid in determining BMD in clinical research, such as Quantitative Computed Tomography (QCT) and Quantitative Ultrasound (QUS). The first method, QCT, obtains volumetric bone measurements. However, the radiation dose is substantially higher per scan, and the cost is higher than DXA[12]. On the other hand, QUS uses the attenuation and speed of sound to assess bone mineral density at the phalanges of the hand and calcaneus [13]. Although QUS is radiationfree, there is variability among devices, with different measurements for the same skeletal site analyzed without applying standard diagnostic criteria [14].

Given that scenario, incorporating effective technologies that can promote health and disease prevention is imperative to provide health systems with scientifically sound resoluteness. Incorporating technologies at the PHC level, from population screening, aims at increasing access to the timely diagnosis of osteoporosis while also allowing, more effectively and swiftly, the adoption of guidelines and interventions at early-onset of the disease.

This study aims to validate a hybrid device, Osseus, composed of antennas and developed to perform osteoporosis screening from BMD assessments at the middle phalanx of the middle finger. The analysis is done by determining the electrical permittivity in the bone tissue. The development of the Osseus prototype involved five stages: (1) choice of material, (2) the definition of measures according to the components, (3) creation of embedded software, (4) integration of components, and (5) testing for validation, which we will discuss next.

Alternative methods involving other body regions have been researched, such as the phalanges, to reduce manufacturing costs and increase population access. As confirmed in a study, the dielectric constants for healthy and diseased bones in this region are significantly different. This allows diagnosing osteoporosis by developing a measurement procedure based on electromagnetic waves (EM) propagation in the phalanx [15]. This bone region is particularly favorable because it has little muscle tissue, characterized by high attenuation of EM waves that propagate through it. In this manner, an electromagnetic signal passing through the phalanx will mostly suffer attenuation due to the bone tissue, which can be higher or lower depending on the bone porosity. To validate this method, we initially conducted tests on animal bones. At this time, validation studies involved only attenuation and its relationship with bone density. Currently, the use of Artificial Intelligence (Al) is being investigated in order to introduce other risk factors into the classification system in order to allow prognosis (early detection). 


\section{Results}

The attenuation readings with individual and pooled samples (Table 1) show that the porcine skin (sample A) exerts a higher attenuation compared to a separate plaster cylinder sample (sample B). This result is positive since it indicates Osseus's capability to scan the human finger and handle the difference in attenuation caused by human skin. All the other animal bone samples also revealed higher attenuation in the altered samples.

Table 1: Values of attenuation measurements of intact and altered samples 


\begin{tabular}{|c|c|c|c|c|c|c|}
\hline \multirow[t]{2}{*}{ Type of sample } & \multirow[t]{2}{*}{ Name } & \multicolumn{2}{|c|}{ Weight (g) } & \multicolumn{2}{|c|}{ Reading (mV/GB) } & \multirow[t]{2}{*}{ Difference } \\
\hline & & Original & Altered & Original & Altered & \\
\hline \multirow[t]{9}{*}{ Bovine bone } & $\mathrm{A} 1$ & 204.2 & 198.6 & 38.8783 & 38.6707 & 0.2076 \\
\hline & $\mathrm{A} 2$ & 142.9 & 137.2 & 39.7907 & 39.5220 & 0.2687 \\
\hline & A3 & 145.3 & 141.0 & 40.3946 & 40.3184 & 0.0762 \\
\hline & B1 & 148.3 & 144.2 & 43.7795 & 42.8605 & 0.9190 \\
\hline & B2 & 139.3 & 133.1 & 40.5919 & 39.9600 & 0.6319 \\
\hline & B3 & 120.6 & 117.1 & 38.9521 & 38.8154 & 0.1367 \\
\hline & $\mathrm{C} 1$ & 123.0 & 120.2 & 39.9055 & 39.8818 & 0.0237 \\
\hline & $\mathrm{C} 2$ & 145.7 & 143.4 & 41.5019 & 40.8901 & 0.6118 \\
\hline & $\mathrm{C} 3$ & 132.6 & 123.4 & 40.4362 & 38.9570 & 1.4792 \\
\hline \multirow[t]{4}{*}{ Porcine bone } & 01 & 25.1 & 24.9 & 118.9343 & 113.3658 & 5.5685 \\
\hline & 02 & 24.7 & 23.6 & 78.0485 & 68.1080 & 9.9405 \\
\hline & 03 & 25.1 & 24.8 & 56.9531 & 50.6250 & 6.3281 \\
\hline & 04 & 25.6 & 24.6 & 82.2656 & 64.4778 & 17.7878 \\
\hline \multirow[t]{5}{*}{ Galliformes bone } & 01 & - & - & 31.6406 & 25.3125 & 6.3281 \\
\hline & 02 & - & - & 25.3125 & 15.8203 & 9.4922 \\
\hline & 03 & - & - & 15.8203 & 9.4922 & 6.3281 \\
\hline & 04 & - & - & 60.1172 & 28.4700 & 31.6472 \\
\hline & 05 & - & - & 31.6406 & 28.4765 & 3.1641 \\
\hline Porcine Skin & A & - & - & 155.0390 & 144.1530 & 10.8860 \\
\hline Plaster & B & - & - & 50.1294 & 45.7611 & 4.3683 \\
\hline Plaster and porcine skin & C & - & - & 208.8281 & 183.5156 & 25.3125 \\
\hline
\end{tabular}

The device Osseus demonstrated effectiveness in the attenuation measurements, as the attenuation of the signal was recorded in the analyses of the altered samples in all tests (Table 1).

\section{Discussion}

The first trials of Osseus have demonstrated effectiveness in measuring bone mineral density in animal models and have proven that it can handle the complexity of the tissues inside bones. A device similar to 
Osseus was developed by [16]. However, it was applied to the forearm, specifically, in the distal region of the radius and the ulna. Its two antennas operate in the $0-2 \mathrm{GHz}$ band and have a radiofrequency configuration that radiates $0.1 \mathrm{~W}$ of power. As for the results, the researchers observed healthy and osteopenic/osteoporotic states across sixty participants (23-94 years old, 48 women, 12 men). Nonetheless, that study employs a licensed frequency band (except for the range between $902-928 \mathrm{MHz}$, the lowest ISM band). That is to say, typical commercial applications, such as analog and digital TV or even the signal from a simple cell phone, represent interfering signals and can cause measurement errors. Hence, one aspect to consider is the necessity of electromagnetic shielding surrounding the antenna pair's emitting and receiving space, which was not referred to in the article.

Also, regarding [16], it should be pointed out that, after positioning the antenna pressed into the forearm region, it was not mentioned whether the signal would be received in the far-field region. In cases where the antennas are positioned too close together, such as for slim forearms, the signal might be received in the near-field region, where its characteristics will be unpredictable and measurements inaccurate.

Further, despite the designated region being mainly constituted of bone tissue, in patients with a high percentage of fat, the other tissues may be relevant, to the point of altering the measurements. Last, to definitively validate the device's measurements, it is essential to compare them with an existing test (preferably DXA because it is the gold standard) under the same conditions. That will probably result in the need to process the measured signals to introduce other variables for the expression proposed in the study. The intent is to obtain a final result for each diagnosis that is reliable and more accurate.

Another research work developed using EM wave techniques for osteoporosis diagnosis was proposed [15] to qualify the relative electrical permittivity of bone tissue. In this vein, it sought to identify values compatible with healthy subjects and those with low BMD. The method is based on measuring the middle phalanx of the middle finger with an antenna positioned on one side and a reflective surface on the other. The reported results use a previous test of patients' bone densitometry (DXA) as a reference. In addition, considering that a very porous bone tissue characterizes a lower permittivity than a healthy one, the researchers proposed scores for frequency deviation values (concerning the resonance frequency of the antenna used in the diagnosis) to classify the patients as healthy, having low BMD, or having osteoporosis.

However, as mentioned in [15], some significant parameters, such as finger dimensions, are not yet considered. Moreover, no differences regarding patients' age, gender, fat percentage, or any other potentially relevant aspects were mentioned in the study. Also, no reference was made to electromagnetic protection to confine the signals used in the diagnosis, which would arguably prevent external interferences from modifying the values obtained.

Osseus is currently undergoing validation for use in human subjects, with ethics committee approval (CAEE 39675020.0.0000.5292, HUOL/UFRN), through tests that assure the device's accuracy regarding the gold standard, DXA, in supporting the diagnosis of osteoporosis. The results might be influenced by a survey conducted with patients, including risk factors variables and anthropometric measurements of the 
middle phalanx of the middle finger, where the scanning is performed. A tablet will be used to perform a survey on risk factors, and the data will be pre-processed and stored in the cloud for further analysis. The device has an LCD that, in the future, may also be used to conduct the survey.

The intelligent analysis local system will be to run the models using as inputs only the individual's data (models to be periodically trained in the cloud and updated in Osseus) and the global intelligent data analysis system (cloud) will be more focused on training prognostic models using data from many individuals in order to identify risk factors, their progression and therefore early detection. Artificial intelligence application proves to be suitable for the prognosis of the disease or fracture since there is no need to provide a diagnostic criterion to identify osteoporosis, but a set of examples that represent the variations of the disease. Additionally, a number of classification algorithms and methods have been applied to machine learning problems [17-19]. However, it has been observed that it takes more than merely choosing an algorithm and running it over the data for such learning to be successful. That is, many learning patterns can have a diversity of parameters. Such patterns must therefore be appropriately selected for better classification results to be obtained.

Thus, there is a lack of a unified system with different databases and the grouping of the various attributes and clinical factors for achieving a broader coverage of different populations when identifying risk groups. For instance, these factors should include male participants, broader age groups, and race. Risk factors are of valuable help when it comes to identifying groups with a potential for osteoporosis. However, when individually analyzed, such factors are insufficient to track the groups. So, it is necessary

to cross-reference information from previously performed tests and then use an artificial intelligence tool for treating data.

Al and in particular neuronal networks has been demonstrated potential to diagnostic/classification problems in the clinical area and in particular in osteoporosis [20-23]. In addition, it is expected to be able to identify the risk factors that most influence the progression of the disease and, thus, to be able to develop models for early detection.

\section{Conclusions}

Predicting the risk groups for osteoporosis may mitigate the substantial financial burden on health care systems due to osteoporotic fractures. Considering that the pattern of change of BMD with age is reasonably well understood, and the inexistence of independent contribution of BMD to fracture risk, being necessary to associate it with somatic factors, several methods make use of the integration of artificial intelligence with risk factors to screen groups at high risk for osteoporosis or fractures. Given that screening is intended to direct interventions for those necessitating the diagnosis of osteoporosis, the tests must be of high specificity. In this context, the most significant variables were chosen for a survey to be performed with humans for testing in future work.

Finally, another field of activity of our project is the development of progressively smaller Osseus devices with greater portability and lower manufacturing costs. Of note, it will be necessary to carry out tests 
using different artificial intelligence approaches, owing to the complexity of the data that this tool will have to deal with throughout clinical trials. Therefore, it will be possible to have a predictive tool that can be applied to populations with more individuals-including males, since most studies focus on females, regardless of their age or ethnicity.

\section{Methods}

\section{Antennas}

An antenna is a device that beams EM waves into free space. Typically, the antenna is powered by a transmission line, such as a microstrip line or a coaxial cable, which transmits signals from the transmission source to the antenna [24]. Over the past few years, several types of medical applications that use antennas have been thoroughly investigated and reported, including diagnosis and treatment of different chronic diseases [25]. Among the existing types, the Yagi-Uda antenna, or simply Yagi antenna, features high directivity and, consequently, high gain in the direction of maximum energy radiation. This antenna consists of multiple director elements, which conduct the electromagnetic signal to the halfwavelength dipole, the element through which the signal is injected, called the radiator element, and a reflector element placed behind the half-wave dipole. Hence, the half-wave dipole is powered by the transmitter signal, which generates a current distribution along its length, resulting in the radiation of electromagnetic waves. Next, given their mutual coupling with the closest element, the director elements guide the electromagnetic radiation due to the current induction generated by the previous elements [24].

In this way, the pair of antennas used on Osseus corresponds to the model WA5VJB (Figure 2), marketed by Kent Electronics. This pair was designed to operate in a $2.4-2.48 \mathrm{GHz}$ frequency range, and it has a radiation diagram, as indicated in Figure 3.

Additionally, it is typical for electronic circuits near the antennas to be sensitive to electromagnetic interference (EMI), and it is necessary to protect them from this effect. The technique used for such a process is called shielding, and it can be accomplished by several means. One of the simplest shielding methods for external interference is to surround the circuit with a metal box, usually made out of aluminum, responsible for reflecting these EM waves and thus preventing them from reaching the circuits.

\section{Electromagnetic Shielding}

Shielding can attenuate an electromagnetic wave. Such attenuation occurs through the reflection of the incident wave due to the use of conductive material in the shielding, like iron, steel, copper, or aluminum, the latter being more versatile and low cost. Then, its efficiency is calculated as a ratio of the power inside and that outside the shielding [26]. 
With the need to protect measurement equipment, applying EM shielding has become relevant, especially in electronic devices used in the medical field. Those are composed of sensitive analog amplifiers, microprocessors that can be affected by EM interference, among others.

Internally, there is a need to prevent the signal radiated by the transmitting antenna from reflecting off on the metallic walls of the box and returning to the electronic circuitry. Therefore, it makes it necessary to coat the metal box internally with an absorbing material. Electromagnetic absorbers are composed of materials that absorb the incident EM radiation in specific frequency ranges and release it as heat. These materials are obtained from the appropriate processing of polymeric matrices that act as absorbing centers for the incident radiation. This study used Eccosorb $A N$ microwave absorbers designed to strongly attenuate a specific frequency range, confining the signal within the box and avoiding successive reflections on the metallic walls. Such absorbers are made of polyurethane foam treated with carbon and mounted on a laminated surface to generate a controlled conductivity gradient [27].

\section{Electronic Devices}

When it comes to Osseus, the processor is another significant device. Processors are devices of a few square centimeters in size and with high processing power. They can operate analog-to-digital conversions, with the ability to deliver results in a graphical environment over a computer network, perform data analysis, and compute them in a neural network by receiving programming instructions.

Osseus integrates a microcontroller with other peripheral devices to perform the tasks necessary to measure EM permittivity. Figure 4 depicts the flow of the device's operation. Thus, an operator fills in the patient's characteristics on an electronic form, performs the signal attenuation measurement, with no barrier between the antennas, selecting the point (frequency of the injected signal) of highest received power so that it can serve for reference or calibration. Then, the permittivity test is performed on the patient's finger. After that, the equipment (figure 5) displays the values obtained and sends the data for cloud storage and post-processing.

The device, through one of its antennas, emits an EM wave in a predefined frequency range. Then, on the opposite side, a similar antenna receives that wave, attenuated by the obstacle corresponding to the patient's finger-specifically, the middle phalanx of the middle finger. A circuit coupled to the antenna identifies the analog signal strength and converts it into a digital signal. Then, based on the patient's characteristics and the signal attenuation, the microcontroller can process the information to indicate whether or not the individual needs to get a DXA scan.

For generating the targeted frequency, we used a Voltage-controlled Oscillator (VCO). This component can generate a sinusoidal signal at a frequency that depends on the voltage applied to its input, and it is located at the transmitter side of the signal. On the opposite side, an RF Power Detector is connected to the receiving antenna. The sensor converts the received RF intensity into voltage so that it can be processed. 
To obtain the desired directivity, we used a pair of Yagi Uda antennas printed on a fiberglass substrate, with dimensions of $6.6 \mathrm{~cm} \times 7.0 \mathrm{~cm}$, one being a transmitter and the other a receiver, operating in the frequency range of $2.45 \mathrm{GHz}$ [28], fed by a microstrip line. After the prototype's three-dimensional modeling, we proceeded with the fabrication of the components. Part of it was manufactured with a 1.6 $\mathrm{mm}$ thick aluminum, ensuring a high standard of EM shielding, another in translucent acrylic, and the remaining components in a 3D printer. On the inside, the equipment has been coated with absorbing material designed for a $2.44 \mathrm{GHz}$ frequency.

\section{Proof of Concept}

We have performed simulations to prove the operation of the device using samples of orthodontic plaster cylinders simulating human bone and encased in porcine skin. This kind of skin has been recommended for studies since it has physiological, histological, biochemical similarities and density akin to human skin[29]. Each plaster cylinder was built with only water and plaster, $2 \mathrm{~cm}$ in diameter and $7.5 \mathrm{~cm}$ in height.

Next, we used the femur bones of Galliformes since, besides representing the first bird order associated with humans, such birds have relatively long femur bones[30]. Moreover, we also used bones from the porcine proximal phalanx, given their remarkable similarity to human bone tissue[31] and bones from cattle femurs since they satisfactorily reproduce aspects of human anatomy[32]. First, the samples were classified and analyzed while still intact (original sample) and after undergoing mechanical perforations to increase porosity (altered samples - Figure 6) artificially. According to the perforations, the samples have undergone modifications in their attenuation measurements.

\section{Declaration}

\section{*Ethics approval and consent to participate}

'Not applicable'

\section{*Consent for publication}

'Not applicable'

\section{*Availability of data and material}

All data generated or analysed during this study are included in this published article and its supplementary information files.

\section{*Competing interests}

The authors declare that they have no competing interests. 


\section{*Funding}

Universidade Federal do Rio Grande do Norte Recipient: Ricardo Valentim Alexsandro de Medeiros, Doctor

\section{*Authors' contributions}

AS, GA, DC, BP: collection, organizing, and review of the literature; preparing the manuscript. AC, RV, NM, $\mathrm{JH}, \mathrm{JL}$ : manuscript review, modification, editing, and revision. Both authors read and approved the final manuscript.

\section{*Acknowledgements}

We want to thank the Laboratory of Technological Innovation in Healthcare at the Federal University of Rio Grande do Norte and the Advanced Technological Innovation Nucleus of the Federal Institute of Rio Grande do Norte to support in carrying out this work.

\section{References}

1. Massuda A, Hone T, Leles FAG, Castro MC, Atun R. The Brazilian health system at crossroads: progress, crisis and resilience. BMJ Glob Health. 2018; 3. http://dx.doi.org/10.1136/bmjgh-2018000829

2. Brasil: Ministério da Saúde. Número de equipes de saúde da família. http://tabnet.datasus.gov.br/cgi/tabcgi.exe?cnes/cnv/equipebr. Acessed 20 february 2021.

3. Macinko J, Mendonça CS. Estratégia Saúde da Família, um forte modelo de atenção primária à saúde que traz resultados. Saúde Debate. 2018; 42:18-37. https://doi.org/10.1590/0103$11042018 S 102$

4. Castro AL, Andrade CL, Machado CV, Lima LD. Condições socioeconômicas, oferta de médicos e internações por condições sensíveis à atenção primária em grandes municípios do Brasil. Cad Saúde Pública. 2015; 31:2353-2366. https://doi.org/10.1590/0102-311X00126114

5. Tasca R, Massuda A, Carvalho WM, Buchweitz C, Harzheim E. Recommendations to strengthen primary health care in Brazil Recomendaciones para el fortalecimiento de la atención primaria de salud en Brasil. Pan Am J Public Health. 2020; 44. https://doi.org/10.26633/RPSP.2020.4

6. Johnell 0 , Kanis JA. An estimate of the worldwide prevalence and disability associated with osteoporotic fractures. Osteoporos Int. 2006; 17:1726. https://doi.org/10.1007/s00198-006-0172-4

7. Gullberg B, Johnell O, Kanis JA. World-wide projections for hip fracture. Osteoporos Int. 1997; 7:40713. https://doi.org/10.1007/PL00004148

8. Aziziyeh R, Amin M, Habib M, Garcia PJ, Szafranski K, McTavish R K, Cameron C. The burden of osteoporosis in four Latin American countries: Brazil, Mexico, Colombia, and Argentina. J Med Econ. 2019; 22:638-644. https://doi.org/10.1080/13696998.2019.1590843 
9. Hans DB, Shepherd JA, Schwartz EN, Reid DM, Blake GM, Fordham JN, Lewiecki EM. Peripheral dualenergy X-ray absorptiometry in the management of osteoporosis: the 2007 ISCD Official Positions. J Clin Densitom. 2008; 11:188-206. https://doi.org/10.1016/j.jocd.2007.12.012

10. Brasil: Ministério da Saúde. Existing densitometry equipment in Brazil. http://tabnet.datasus.gov.br/cgi/tabcgi.exe?cnes/cnv/equipobr.def. Acessed 20 may 2021.

11. International Osteoporosis Foundation. Auditoria Regional da America Latina https://www.osteoporosis.foundation/educational-hub/files/latin-america-regional-auditepidemiology-costs-burden-osteoporosis-2012. Acessed 25 Jan 2021.

12. Burghardt AJ, Link TM, Majumdar S. High-resolution computed tomography for clinical imaging of bone microarchitecture. Clin Orthop Relat Res. 2011; 469:2179-2193. https://doi.org/10.1007/s11999-010-1766-x

13. Hans D, Baim S. Quantitative ultrasound (QUS) in the management of osteoporosis and assessment of fracture risk. J Clin Densitom. 2017; 20:322-333. https://doi.org/10.1109/TUFFC.2008.829

14. Zaidman CM, Holland MR, Hughes MS. Quantitative ultrasound of skeletal muscle: reliable measurements of calibrated muscle backscatter from different ultrasound systems. Ultrasound Med Biol. 2012; 38:1618-1625. https://doi.org/10.1016/j.ultrasmedbio.2012.04.020

15. Vendik IB, Odit MA, Kirillov VV, Tamilova S, Yakovlev VA, Zolototrubov K, Pleskachev VV. Diagnostics of osteoporosis based on analysis of electromagnetic wave propagation in biological objects. In 2019 Antennas Design and Measurement International Conference (ADMInC). 2019; 58-61. https://doi.org/10.1109/ADMInC47948.2019.8969252

16. Makarov SN, Noetscher GM, Arum S, Rabiner R, Nazarian A. Concept of a radiofrequency device for osteopenia/osteoporosis screening. Sci rep. 2020; 10: 1-15.

17. Cruz AS, Silva SG, Castro BH. Bone density measurement through electromagnetic waves. In The 6th 2013 Biomedical Engineering International Conference. 2013; 1-5. https://doi.org/10.1109/BMEiCon.2013.6687655

18. Maity NG, Das S. Machine learning for improved diagnosis and prognosis in healthcare. In 2017 IEEE Aerospace Conference. 2017; 1-9. https://doi.org/10.1109/AER0.2017.7943950

19. Emanet N, Öz HR, Bayram N, Delen D. A comparative analysis of machine learning methods for classification type decision problems in healthcare. Decis Anal. 2014; 1:1-20. https://doi.org/10.1186/2193-8636-1-6

20. Li JP, Haq AU, Din SU, Khan J, Khan A, Saboor A. Heart Disease Identification Method Using Machine Learning Classification in E-Healthcare. IEEE Access. 2020; 107562-107582. https://doi.org/10.1109/ACCESS.2020.3001149.

21. Iliou T, Anagnostopoulos CN, Stephanakis IM, Anastassopoulos G. A novel data preprocessing method for boosting neural network performance: A case study in osteoporosis prediction. Inf Sci. 2017; 380:92-100. https://doi.org/10.1016/j.ins.2015.10.026

22. Liu Q, Cui X, Chou YC, Abbod MF, Lin J, Shieh JS. Ensemble artificial neural networks applied to predict the key risk factors of hip bone fracture for elders. Biomed Signal Process Control. 2015; 
21:146-156. https://doi.org/10.1016/j.bspc.2015.06.002

23. Yu X, Ye C, Xiang L. Application of artificial neural network in the diagnostic system of osteoporosis. Neurocomput. 2016; 214:376-381. https://doi.org/10.1016/j.neucom.2016.06.023

24. Leslie WD, Lix LM, Yogendran MS. Validation of a case definition for osteoporosis disease surveillance. Osteoporos Int. 2011; 22:37-46. https://doi.org/10.1007/s00198-010-1225-2

25. Sartorelli P, Andersen HR, Angerer J, Corish J, Drexler H, Göen T, Williams F. Percutaneous penetration studies for risk assessment. Environ Toxicol Pharmacol. 2000; 8:133 - 152. https://doi.org/10.1016/S1382-6689(00)00035-1

26. Hwang PW, Chen AP, Lou CW, Lin JH. Electromagnetic shielding effectiveness and functions of stainless steel/bamboo charcoal conductive fabrics. J Ind Text. 2014; 44(3), 477-494.

27. Emerson., C. ECCOSORB AN - Flexible foam sheet broadband microwave absorbers, Randolph, MAd. 2011.

28. Oliscovicz NF, Valente MLDC, Marcantonio Junior E, Shimano AC, Reis ACD. Estudo in vitro da influência do formato e do tratamento de superfície de implantes odontológicos no torque de inserção, resistência ao arrancamento e frequência de ressonância. Rev Odontol UNESP. 2013; 42:283-290.

29. Galia CR, Macedo CADS, Rosito R, Mello TMD, Diesel C, Moreira LF. Caracterização físico-química de ossos liofilizados de origem bovina e humana. Rev Col Bras Cir. 2009; 36:157-160. https://doi.org/10.1590/S0100-69912009000200013

30. Balanis C. Teoria de Antenas - Análise e Síntese. Rio de Janeiro,RJ; 2009.

31. Kaur G, Kaur A, Toor GK, Dhaliwal BS, Pattnaik SS. Antennas for biomedical applications. Biomed Eng Lett. 2011; 5:203-212. https://doi.org/10.1007/s13534-015-0193-z

32. Hwang PW, Chen AP, Lou CW, Lin JH. Electromagnetic shielding effectiveness and functions of stainless steel/bamboo charcoal conductive fabrics. J Ind Text. 2014; 44:477-494. https://doi.org/10.1177/1528083713502995

\section{Figures}




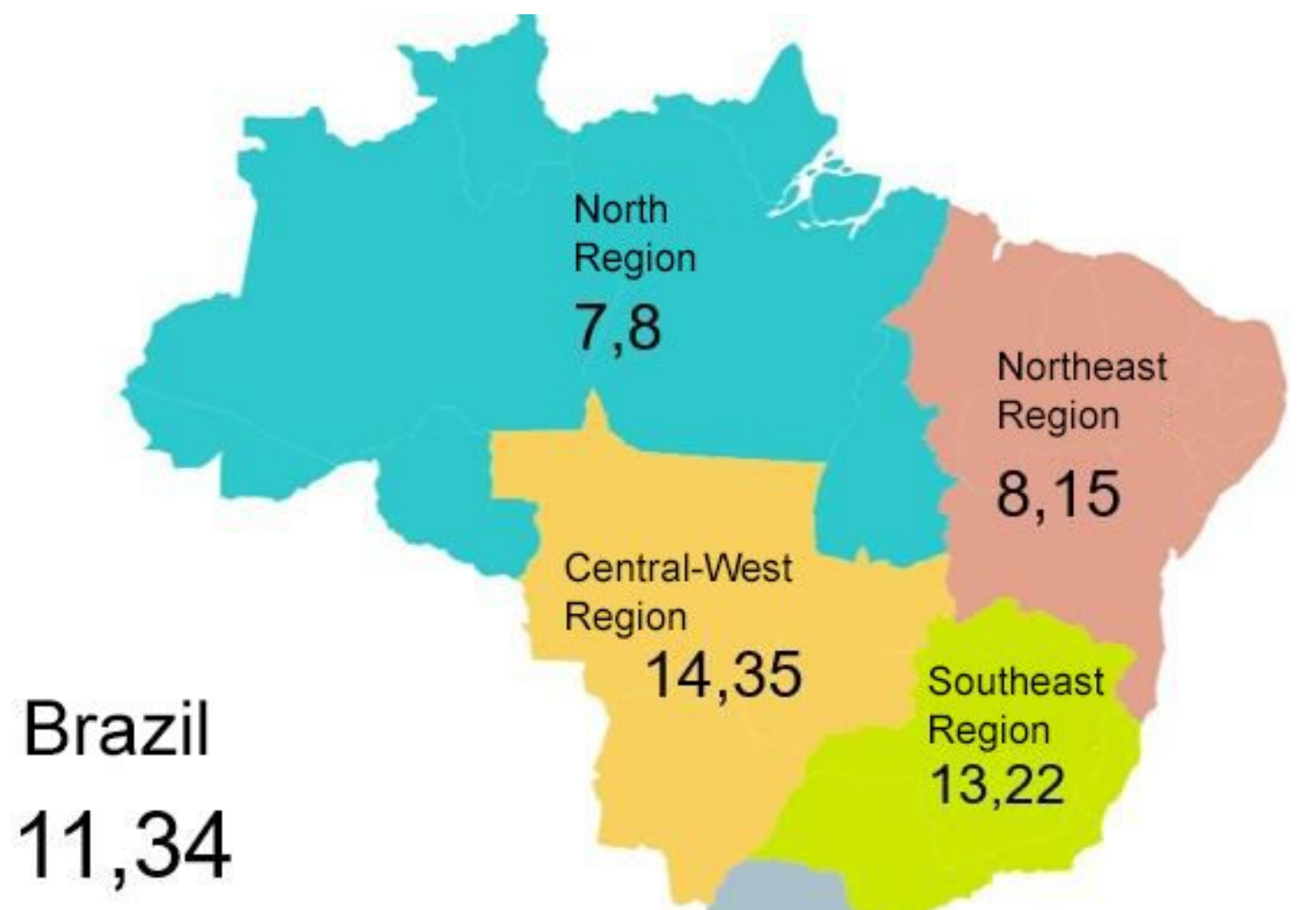

Devices per $1,000,000$ inhabitants South

Region

13,03

Figure 1

Availability of bone densitometry devices per Brazilian region

原

Figure 2

Antenna used on Osseus 


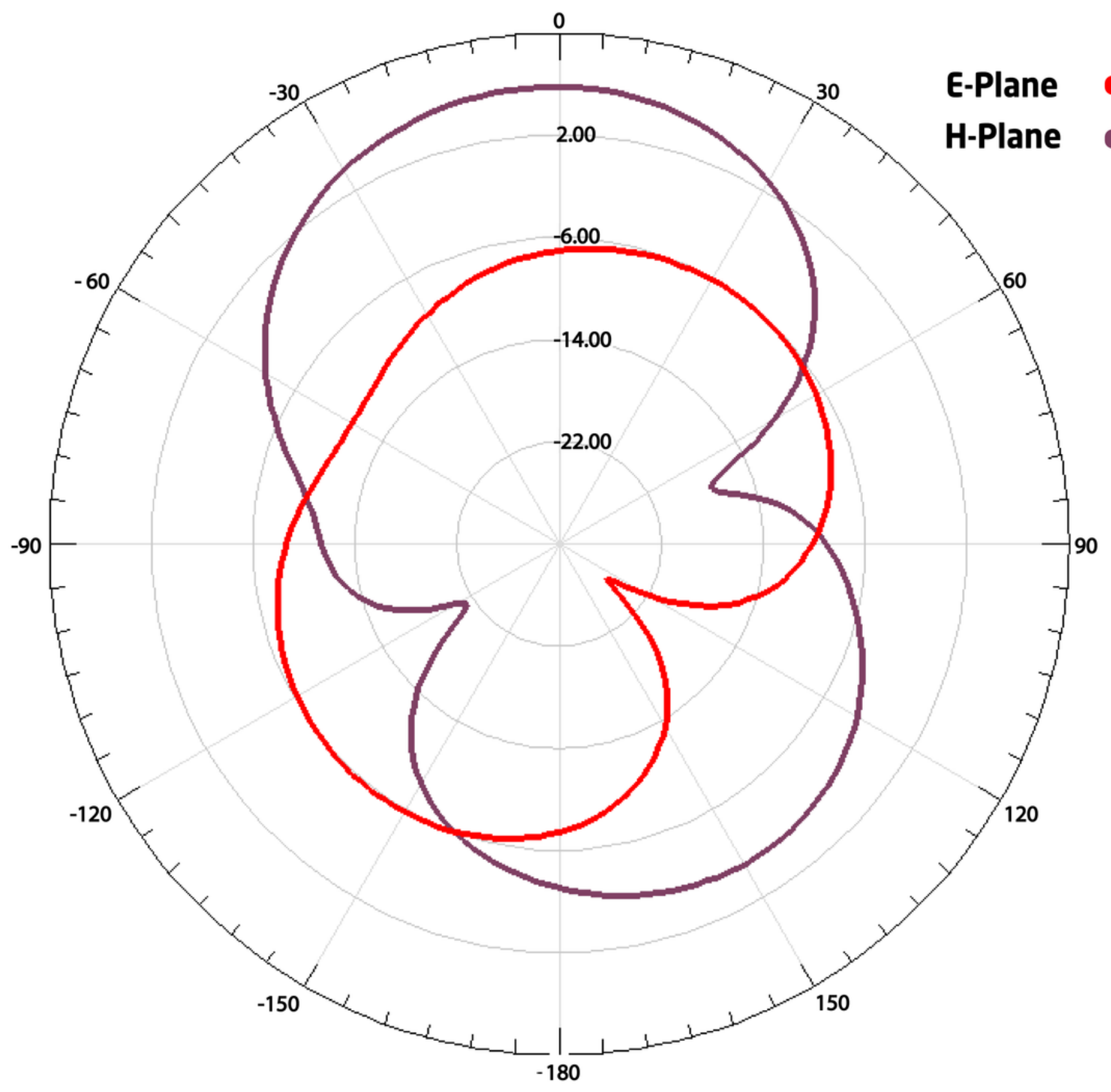

Figure 3

Radiation diagram of the Osseus antennas 


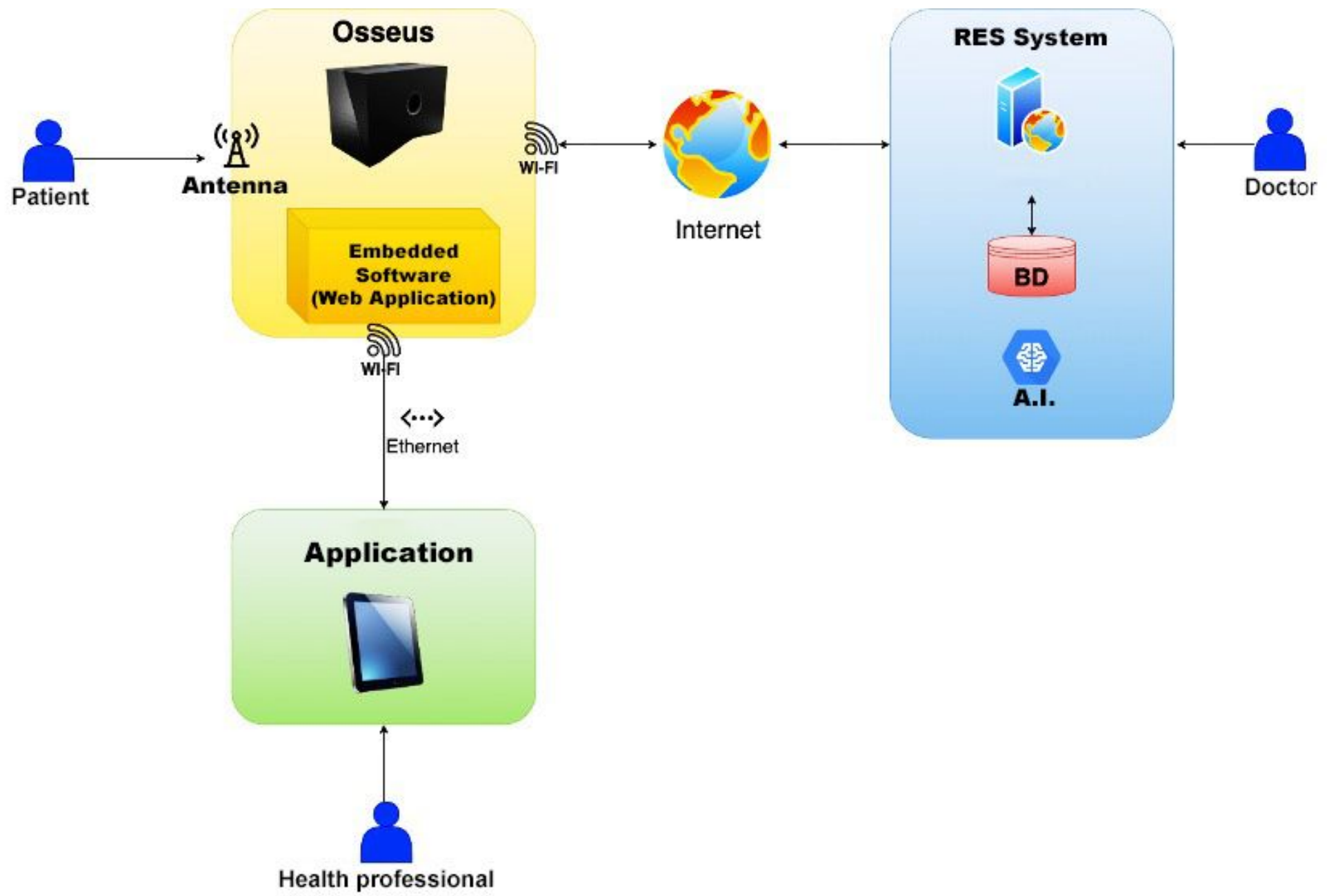

Figure 4

Operation flow of the Osseus device 


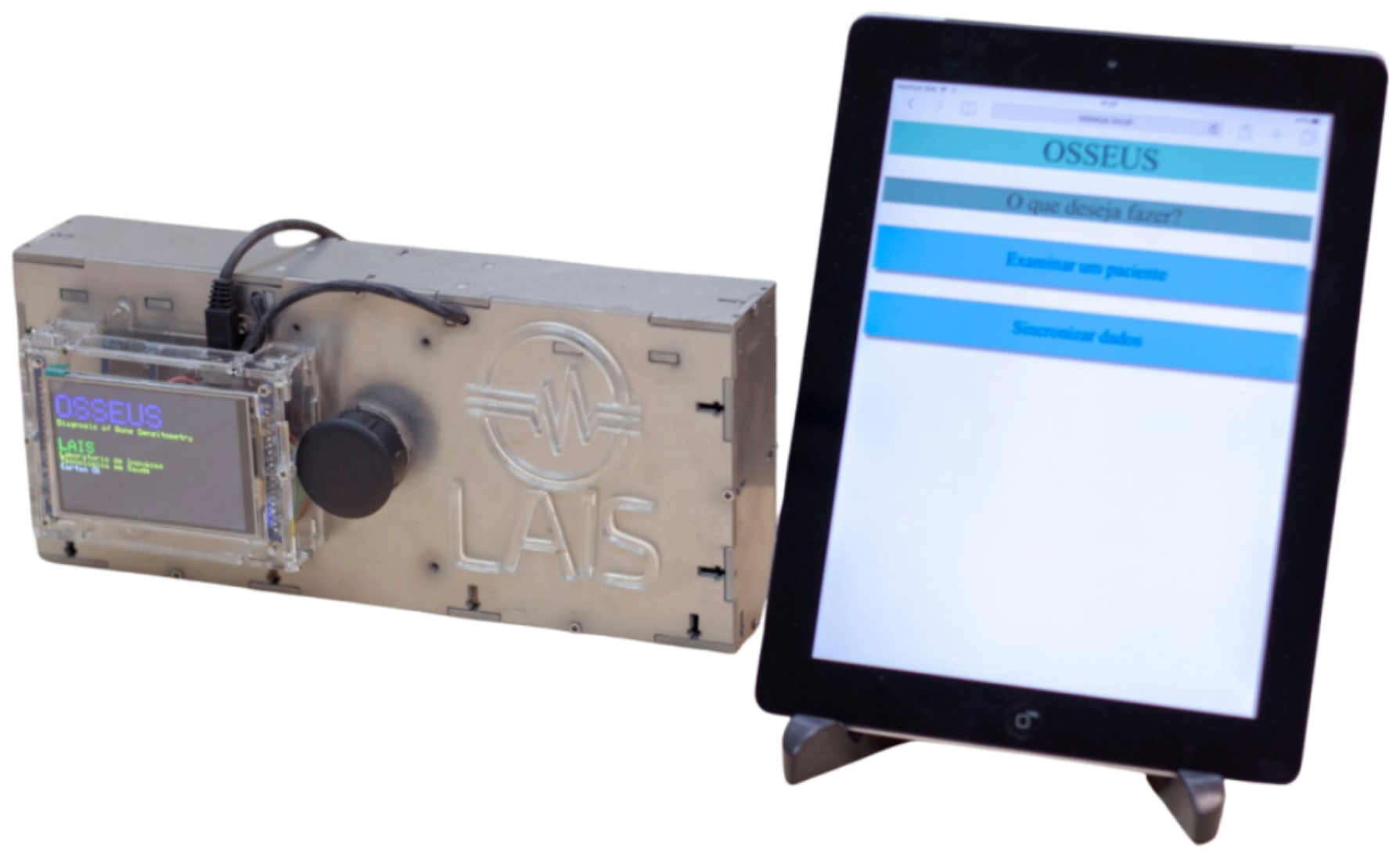

Figure 5

Osseus prototype 

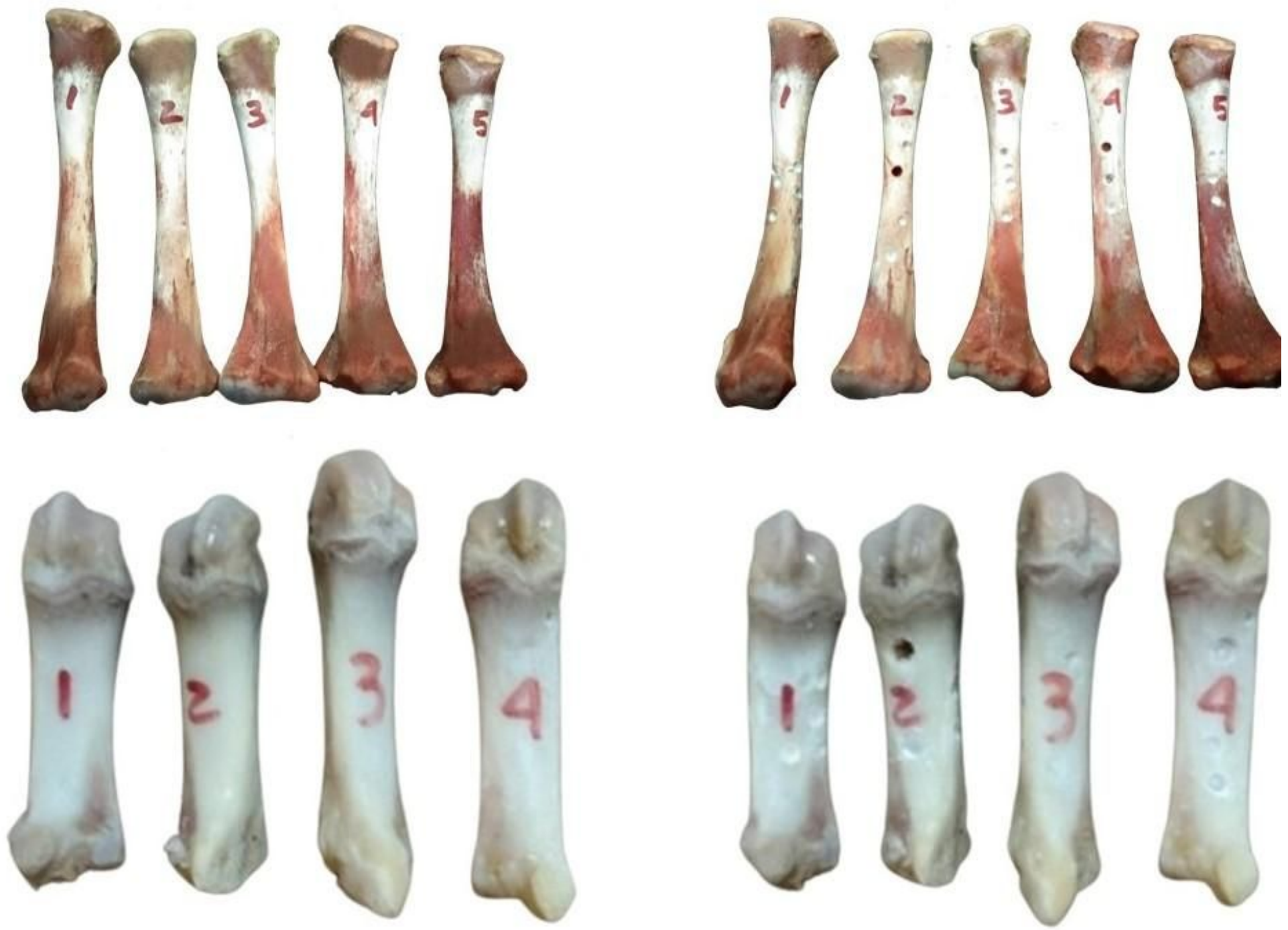

Figure 6

Intact and altered samples of galliformes and porcine bones used for proof of concept 